\title{
Passando a limpo: um passeio pelos processos e pelos projetos de revitalização urbana do Meatpacking District, em Nova York, e da Região da Luz, em São Paulo
}

Janaina Maquiaveli. Belo Horizonte, Brasil.

RESUMO | O texto que segue é parte de um estudo comparativo entre os processos de revitalização urbana do Meatpacking District, em Nova York, e os projetos de revitalização da Região da Luz, em São Paulo. O artigo tem por objetivos transitar pelos principais paradigmas da sociologia urbana, destacar as formas de sociabilidade típicas dos grandes centros e refletir a respeito de como a sociologia contemporânea vem sendo exigida de uma revisão acerca do que são as cidades. Tudo isto tendo em vista os processos de revitalização urbana e gentrification, cada vez mais frequentes em diferentes cidades ao redor do mundo.

PALAVRAS-CHAVE | Urbanismo, urbanização, vulnerabilidade.

ABSTRACT | The text below is part of a comparative study between the urban revitalization process of the "Meatpacking District" in New York City, and the urban revitalization projects of Região da Luz, in Sao Paulo, Brazil. The article's objectives are to undertake a critical overview of the main urban sociology theories and to reflect about the ways in which comtemporary sociology is being in need of a revision of its definitions about what cities are. This analysis considers the processes of urban revitalization and gentrification, that are becoming more frequent in cities all over the world.

KEY WORDS | Urbanism, urbanization, vulnerability. 


\section{Introdução}

As cidades, como os sonhos, são construídas por desejos e medos, ainda que o fio condutor de seu discurso seja secreto, que as suas regras sejam absurdas, as suas perspectivas enganosas, e que todas as coisas escondam uma outra coisa. (...) As cidades também acreditam ser obra da mente ou do acaso, mas nem um nem outro bastam para sustentar as suas muralhas. De uma cidade, não aproveitamos as suas sete ou setenta e sete maravilhas, mas a resposta que dá às nossas perguntas. Ou às perguntas que nos colocamos para nos obrigar a responder, como Tebas na boca da Esfinge.

As cidades como narrativas fazem parte da história do pensamento sociológico, assim como, de modo recorrente, do universo literário, tal como se pode encontrálas no livro de Calvino. O olhar do escritor, do viajante, do pesquisador sempre busca ultrapassar os limites da geografia ao descrever as cidades que observa, ou até mesmo as cidades que se escondem numa outra, a cidade oficial, a dos mapas e dos cartões postais, a das passagens e das paisagens, tal como descrevera Benjamim (1985, 2006) em Paris, capital do século XIX.

No entanto, ao andar pelas ruas de uma grande cidade, hoje em dia, nem sempre é possível encontrar o que, na sociologia, definiu a vida urbana e moderna, tal como retratada, de modo paradigmático, pelo olhar benjamimniano que transitara por entre as ruas de Paris. Talvez por isso seja necessário perguntar-nos o que restou dos paradigmas que fizeram das cidades importante objeto de estudo das ciências sociais, tendo em vista os cenários nos quais se transformou o espaço urbano, na contemporaneidade. Seria possível, por exemplo, falar em uma natureza peculiar das cidades, tal como fizera a pesquisadora e ativista Jane Jacobs na Nova York dos anos 1960 ? O que pode ter restado dos lugares, para além das demolições e das reconstruções ocasionadas por projetos urbanísticos grandiosos como os de Hausssmann, no século XIX, ou de Robert Moses, nos anos 1960, contra o qual militara Jacobs? E o que dizer das cidades, hoje em dia? Ao invés de demolidas, não estariam sendo simplesmente passadas a limpo por iniciativas cada vez mais recorrentes e reincidentes de revitalização urbana e gentrification ${ }^{1}$

Neste artigo, apresentaremos alguns aspectos relacionados à urbanização de Nova York e São Paulo, de modo a introduzir os estudos comparativos sobre os processos e os projetos de revitalização do Meatpacking District, na primeira, e da Região da Luz, na segunda. Para tanto, transitaremos pelos principais paradigmas da sociologia urbana; destacaremos as formas de sociabilidade típicas dos grandes centros e refletiremos sobre como a sociologia contemporânea vem sendo exigida de uma revisão acerca do que são as cidades.

1 O conceito de gentrification está diretamente ligado às iniciativas de ocupação, pelas classes médias, de antigos bairros e regiões geralmente industriais de grandes cidades europeias e norte-americanas transformados, através de iniciativas ou processos de revitalização urbana, em espaços de consumo simbólico e cultural (Smith, 2006; Zukin, 2000, 2010). 


\section{As cidades como objeto de estudo das ciências sociais}

\section{A sociologia clássica e a Escola de Chicago}

No final do século XIX, as mudanças decorrentes dos processos de industrialização e modernização social transformaram as cidades em objeto de estudo de diferentes campos científicos. Nas ciências sociais, elas passaram a ser definidas como artefatos, uma espécie de materialização do tipo de sociedade originária da Revolução Industrial, cujos processos de urbanização promoveram a coexistência e o trânsito, harmoniosos ou não, de uma diversidade de classes, estratos e categorias sociais em um mesmo espaço geográfico, o espaço urbano metropolitano, então marcado por formas bastante características de sociabilidade (Simmel, 1972; Velho, 1987; Elias, 1994).

A partir dos anos 1920, a análise das relações entre espaço e sociedade foi significativamente ampliada pela Escola de Chicago, já que seus estudos conseguiram transpor os conceitos de diversidade e de interação social, do modo como articulados por Simmel, para o campo da investigação empírica e experimental. O ponto central dos trabalhos de Robert Park (1987), um de seus fundadores, foi identificar na cidade características da sociabilidade urbana descrita pelos clássicos, tais como os modelos de solidariedade, ocupação e divisão do trabalho, ou mesmo os desvios de interações sociais típicas de um modo urbano de vida. Contudo, o mais importante legado de Park foi estruturar a ideia de que há uma correlação entre espaço físico e espaço social. Segundo ele, padrões de gosto, vocabulário, normas e valores socialmente compartilhados estão diretamente ligados à maneira como os indivíduos ocupam o espaço urbano e vice-versa (Becker, 1996).

Herdeiro de Simmel e Park, deve-se a Goffman (1975) e a seus estudos sobre representação social realizados em Chicago a compreensão de que as interações, nas grandes cidades, são dotadas de certas singularidades, como a encenação de papeis e a transitoriedade das práticas cotidianas resultantes do compartilhamento, às vezes provisório, de padrões e de regras de conduta vigentes em cada situação interacional.

Em termos teóricos, os conceitos de segregação, distância social e estigma formulados por Goffman (1975) nos aproximam da ideia de espaço social de Pierre Bourdieu (1999, p. 160), para quem "não há espaço, em uma sociedade hierarquizada, que não seja hierarquizado e que não exprima as hierarquias e as distâncias sociais". Isso explica, sobretudo no Brasil, onde mistura e diversidade são tão comumente utilizadas como elementos de definição de nossa identidade cultural, por que a proximidade geográfica entre grupos tão diversos nem sempre se traduz em interações sociais efetivas, no espaço urbano.

\section{A natureza peculiar das cidades}

De acordo com Jane Jacobs (2000), a efetividade das interações sociais no espaço urbano pode ser tanto maior quanto mais diversificadas forem as cidades, nos diferentes usos e apropriações que se possa fazer delas.

Na prática, há quatro elementos que, segundo Jacobs, garantem a vitalidade e o dinamismo urbanos: i) a multiplicidade de funções, que permite às pessoas transitarem 
e se encontrarem em horários e por razões diferentes; ii) a existência de quadras curtas, que ampliam as possibilidades de circulação pela região onde se vive ou trabalha, criando relações de afinidade com o espaço e a vizinhança; iii) a existência de construçóes com idades e estados de conservação variados, cuja ocupação tende a se dar de forma também diversificada; iv) a alta densidade populacional ocasionada pela mistura de residências, comércio e serviços, garantindo que as pessoas andem pelas ruas em diferentes horários do dia. De acordo com Jacobs, é a coexistência destes elementos que confere às cidades sua particularidade ou, mais propriamente, sua natureza.

No entanto, alguns fatores foram se tornando preponderantes na reconfiguração do espaço urbano a partir dos anos 1950, e não só em Nova York, onde vivia Jacobs, alterando significativamente a natureza peculiar das cidades; o predomínio de modelos progressistas de urbanização, por exemplo, foi um deles. Tanto nos Estados Unidos, em maiores e mais significativas proporções, quanto no Brasil, a diversidade foi sendo gradativamente comprometida pela implantação de modelos de urbanização compartimentados ou monotemáticos, bem como de processos de suburbanização rumo a condados periféricos, no caso americano, ou a bairros situados no entorno das áreas centrais, no caso brasileiro. ${ }^{2}$ Com isso, a cidade como espaço dinâmico, diverso e vivaz foi se tornando decadente e deteriorada, e posteriormente substituída pelo que Henri Lefebvre (1991) e Lawrence Herzog (2006) definiram como espaços simulados de convívio social - como centros fechados e privados de moradia, consumo e lazer-, tanto mais homogeneizados quanto maiores os investimentos internacionais neles empregados.

Ironicamente, no entanto, quando a decadência passou a comprometer seu desempenho econômico e sua capacidade de atração de investimentos, o retorno às cidades foi sendo paulatinamente retomado por diferentes grupos de interesse. $\mathrm{O}$ resultado foi uma série de iniciativas de revitalização urbana que, passando as cidades a limpo, foram marcadas pela oportunidade de retorno financeiro e de visibilidade política, nos anos 1970 e 1980, ou estruturadas como ferramenta estratégica na disputa por investimentos e turismo entre as chamadas cidades globais (Sassen, 2001), a partir dos anos 1990. Todo este cenário acabou estabelecendo uma nova ordem urbana, não se sabe ao certo se mais bonita, mas certamente muito mais intensa do que no cartão postal.

\section{O espaço urbano na pós-modernidade}

Para muitos autores, as sociedades contemporâneas vêm sendo pautadas por um novo modelo de capitalismo, o capitalismo informacional. Nele, a geração de riquezas não depende mais da capacidade produtiva que marcou o modelo industrialista de produção. Ela resulta, sobretudo, da possibilidade de se processar informação e transformá-la em conhecimento. O capitalismo informacional é também global e favorece novas dinâmicas de produção e de consumo, assim como de interação e

2 No Brasil, este tipo de deslocamento tende a variar, geograficamente, conforme a classe social de seus ocupantes: classes média e alta rumo às zonas sul das cidades; classes média-baixa e baixa, rumo às zonas norte, leste e oeste. 
de sociabilidade. De acordo com Canclini (1999), Canevacci (2004) e Lipovetsky (2000), o consumo, mais que o espaço, tornou-se um forte instrumento de produção de sentido nas sociedades contemporâneas. É a partir das escolhas simbólicas e das possibilidades de experimentação de marcas e de produtos que os indivíduos constroem o modo como se inserem na vida em sociedade.

Segundo Harvey (1992) e Smith (2006), o caráter imobiliário e a necessidade de expansão econômica tornaram-se o motor central do urbanismo na pós-modernidade. Para eles, a gestão das cidades ultrapassa a necessidade de administração de recursos financeiros e de infraestrutura, ou mesmo de materialização de ideais políticos, tão característicos do urbanismo modernista e progressista predominantes entre o final do século XIX e meados do século XX. Para Smith, a gestão do espaço urbano tornou-se um critério econômico competitivo, fazendo dos processos de revitalização urbana, bem como dos empreendimentos imobiliários, dos eventos e dos espetáculos internacionais, uma ferramenta estratégica de posicionamento na nova dinâmica do capitalismo global. Exemplo disso tem sido a utilização de técnicas de branding ${ }^{3}$ na promoção de valores e de atributos locais, bem como a criação de rankings entre as chamadas cidades globais. Valendo-se de aspectos como as contribuições da cidade para o mundo nos últimos 30 anos, atributos físicos e climáticos, receptividade e segurança, variedade de atividades culturais e de lazer disponíveis e potencial de crescimento econômico, o Anholt City Brands Index ${ }^{4}$ de 2009, por exemplo, elegeu Paris, Sydney, Londres, Roma e Nova York as cinco marcas de cidade mais bem sucedidas do mundo. [In] felizmente, nenhuma cidade brasileira aparece entre as 30 primeiras colocadas.

\section{As cidades como objeto de consumo}

Não se pode dizer que a gestão das cidades como marcas seja algo recente. No início dos anos 1970, uma série de estratégias visando o reposicionamento e a recuperação econômica de uma cidade drasticamente afetada pela crise financeira teve início em Nova York. Embora reconhecida por seu status cultural, berço de movimentos alternativos como o hip hop, o graffiti e o punk e pela efervescência artística de regiões como Lower East Side e South Bronx, os índices sociais e econômicos da cidade figuravam entre os piores do país. Altas taxas de desemprego e pobreza, crise fiscal, corrupção, criminalidade e violência, somadas ao êxodo de corporações e de residentes rumo aos subúrbios, fizeram de Nova York uma espécie de Meca cultural, porém muito pouco atraente nos cenários financeiro e econômico do país.

Uma ação de marketing capaz de promover a imagem de Nova York foi articulada por investidores imobiliários e bureaus de turismo, viabilizada por uma intensa reestruturação econômica e sustentada pelo poder público local. A proliferação de reportagens, filmes e programas de televisão ressaltando o estilo de vida nova-

3 Branding é uma ferramenta mercadológica cujo objetivo é construir a personalidade de uma marca, fixando-a na mente dos consumidores.

4 Disponível em http://www.business.nsw.gov.au/aboutnsw/lifestyle/E3_citybrandsindex.htm 
iorquino, o incentivo a uma arquitetura grandiosa que marcasse o ressurgimento econômico da cidade e a criação do slogan "Eu amo NY", respaldados por uma forte política de segurança pública baseada em segregação social, transformaram uma cidade underground em lugar amigável, limpo, seguro e propício a investimentos, ou seja, em espaço de consumo (Greenberg, 2008).

De lá para cá, muitas outras estratégias têm sido utilizadas, não só em Nova York, para recuperar e promover a imagem de grandes cidades ou regiões economicamente decadentes. A contratação de projetos excêntricos desenvolvidos por arquitetos renomados, a instalação de franquias de museus internacionais e a transformação de antigas regiões industriais em espaços extravagantes de consumo e lazer, são iniciativas já relativamente consagradas de reconstrução de identidades urbanas locais, tais como: o projeto Docklands, em Londres (1985); a instalação do Museu Guggenheim, em Bilbao (1988); a revitalização do bairro Bercy, em Paris (1992) ou o redesenho do porto comercial de Barcelona (2004). Na América Latina, algo semelhante teve início em 1991 e transformou os antigos galpões do porto do Rio da Prata, construídos entre os anos de 1900 e 1905, em um complexo de lazer, turismo e negócios repleto de hotéis, torres comerciais, restaurantes e casas de tango destinados ao turismo internacional: a região de Puerto Madero, em Buenos Aires (Wilheim, 2005).

No Brasil, ainda que em dimensões mais modestas, cidades como Rio de Janeiro, São Paulo, Salvador, Recife, São Luís e Curitiba passaram, nos últimos anos, por processos de revitalização de suas regiões portuárias ou antigos centros industriais, indicando tanto uma tendência de retorno ao centro (Herzog, 2006), quanto de utilização de recursos internacionais na recuperação de bens arquitetônicos e culturais, ${ }^{5}$ como é o caso do Monumenta, um programa de recuperação do patrimônio histórico brasileiro financiado pelo Banco Interamericano de Desenvolvimento (BID).

\section{O papel das iniciativas de revitalização urbana}

Todo este cenário nos leva a deduzir que as estruturas sociais, culturais e econômicas da pós-modernidade têm alterado de modo significativo o espaço urbano, fazendo das iniciativas de revitalização uma estratégia importante de atração dos fluxos internacionais de investimento, lazer e turismo em diferentes cidades ao redor do mundo. No entanto, como na maioria dos casos as áreas revitalizadas permanecem desconectadas da teia urbana ao seu redor, graças ao predomínio de um determinado uso ou ocupação predominante, não é incomum retornarem às condições de decadência originais, a despeito dos vultosos investimentos empregados na revitalização.

Segundo Jacobs (2000) e Herzog (2006), a vida breve de muitas iniciativas de revitalização urbana deve-se ao fato de serem pensadas como projetos e não como parte integrante do espaço urbano. Para ambos, regióes degradadas devem ser reintegradas à cidade e sua diversidade de ocupaçóes, favorecida; seu entorno deve ser reestruturado, de modo a se tornarem novamente acessíveis e interligadas a regióes onde o dinamismo e a multiplicidade de funções e interações sociais ainda não se 
perderam completamente, sobretudo quando se tratam de regiões de fronteira, como áreas portuárias, estações etc.

Do contrário, regiões revitalizadas desconectadas da malha urbana, centros culturais que, parafraseando Jacobs, não conseguem abrigar sequer uma boa livraria, bulevares e passeios públicos à moda parisiense nos quais é impossível transitar e tantos outros desvios e expropriações do que, em tese, poderiam ser as cidades, serão construídos aqui e ali sob o título de espaços urbanos revitalizados, ou passados a limpo. Não só no Brasil, mas em diferentes lugares onde a revitalização urbana tem se tornado uma prática relativamente bem sucedida, é preciso ressaltar que as cidades não são estáticas e que a transformação de regiões antes vitais em áreas ou espaços decadentes — ou vice-versa - faz parte da transformação permanente de tudo o que é vivo. Resta saber quais são os motores e os agentes da mudança e a quem se destina e interessa o que dela tem, afinal, resultado.

\section{New York, New York ${ }^{6}$}

Em seu livro A Imagem da Cidade, publicado em 1960, o urbanista norte americano Kevin Lynch discutiu o significado da forma urbana para as pessoas que vivem e transitam por uma cidade e como esse significado é traduzido por elas em mapas ou quadros mentais, com os quais apreendem o espaço onde vivem. Através de pesquisas empíricas realizadas em Boston, Jersey e Los Angeles, Lynch descreve como as pessoas percebem e organizam o espaço nas grandes cidades. Vias, limites, bairros, pontos nodais ou de convergência e marcos ou pontos de referência são elementos físicos essenciais na configuração do espaço urbano e, a partir deles, é que os indivíduos observam, percebem e transitam pela cidade, tanto mais legivel quanto maior a possibilidade de seus elementos físicos e visuais serem reconhecidos e organizados.

Quem quer que transite pela ilha de Manhattan, em Nova York, terá uma tradução bastante apropriada do que Lynch definiu como legibilidade. A capacidade de se formular mentalmente uma imagem ambiental da cidade é bastante facilitada pela disposição dos elementos urbanos mencionados por ele. A adoção de coordenadas geográficas e numéricas na disposição das ruas e avenidas, a posição do Central Park, importante ponto de referência na cidade, e a presença de marcos e de construções emblemáticas fazem de Manhattan, um espaço de fácil reprodução mental ou, para usar os termos de Lynch, de grande legibilidade.

Até o início do século XIX, a urbanização de Nova York esteve concentrada no extremo sul da ilha de Manhattan, ocupada inicialmente por colonizadores holandeses e ingleses e, posteriormente, por uma diversidade de imigrantes atraídos pelo intenso comércio da região. Desde o século XVII, no entanto, diferentes fluxos de imigração já conferiam à ilha um caráter cosmopolita. Estima-se que, por volta do ano de 1650, Manhattan tivesse cerca de mil habitantes, mas quase 20 idiomas diferentes, graças aos diversos grupos de imigrantes atraídos pelo ritmo frenético do comércio na região de Wall Street (New York Public Library, 2010).

6 A cidade de Nova York é formada por cinco distritos: Bronx, Brooklyn, Manhattan, Queens e State Island, sendo a ilha de Manhattan o grande centro urbano da cidade e, por que não dizer, a grande representação de NYC. 


\section{Os modelos nova-iorquinos de urbanização em larga escala}

Para impulsionar a urbanização e, com ela, os processos de industrialização e de crescimento econômico, o governo local implantou, entre os anos de 1807 e 1811, o chamado Commissioner's Plan, o primeiro grande projeto de urbanização da cidade. O plano dividiu Manhattan geometricamente em lotes de 8 por 30 metros, cortados por 14 avenidas paralelas e 172 ruas perpendiculares. Seu intuito era conferir à cidade mais conveniência e utilidade a partir de um planejamento urbano racional e higienista (Nolasco, Freitas \& Batista, 2007).

No início do século XX, os impulsos de urbanização acompanharam a aceleração econômica de Nova York, de caráter essencialmente industrialista. Em 1922, por exemplo, quase 23 mil fábricas já haviam sido instaladas em Manhattan, empregando cerca de 520 mil pessoas, 41,5 por cento delas na área têxtil. Na prática, isso exigiu novas intervenções urbanísticas, como pavimentação de ruas, iluminação pública, abastecimento de água, canalização de esgoto e coleta de lixo, ampliadas para conferir à cidade uma estrutura que suportasse o crescimento metropolitano de então (Silva, 2004).

Entre meados do século XIX e começo do século XX, outras iniciativas de reurbanização foram implementadas em Nova York. Muitas delas resultaram da influência de movimentos urbanísticos tais como: a Cidade-Jardim, do inglês Ebenezer Howard; o City Beautiful Movement, do norte-americano Daniel Burnham; e a Ville Radieuse, de Le Corbusier, todos eles fundamentados em princípios ortodoxos e progressistas de urbanização e que pretendiam conferir às cidades aspectos de ordem, modernidade, beleza e grandiosidade. A construção do Central Park, em 1853, da Brooklyn Bridge, em 1883, da Grand Opera House, em 1869, da Estátua da Liberdade, em 1886, da Williamsburg Bridge, em 1903 e do edifício do Grand Central Terminal, em 1913, são exemplos disso. Se, em 1925, a Oitava avenida era escavada para a passagem do metrô e, no final dos anos 1930, a Grand Opera House dava lugar a salas de cinema e máquinas de pipoca, são indícios de uma cidade não só modernizada, mas em constante processo de transformação (Silva, 2004; Talese, 2004).

Já o boom da construção civil teve seu auge em Manhattan entre os anos 1930 e 1970, quando foram erguidas muitas das edificações monumentais da cidade, como o Crysler Building, o Empire State, a ponte Verrazano-Narrows ou, já em 1973, as torres gêmeas [derrubadas pelo atentado de 11 de setembro] do World Trade Center. Estes ícones, que ainda hoje preenchem as páginas dos guias turísticos e dos cartões postais da cidade, quando planejados, visavam impulsionar a reação de Nova York às crises econômicas dos anos 1930, 1950 e 1970, causadas respectivamente pela queda da Bolsa de Valores, em 1929, pelo fim da Segunda Guerra Mundial e pelo déficit orçamentário da cidade.

$\mathrm{Na}$ tentativa de reaquecer a economia local, muitos projetos de reurbanização foram implementados em Nova York por volta dos anos 1950, a maioria sob o comando do construtor Robert Moses, cujos padrões, embora aclamados por sua relativa ousadia, revelavam uma visão um tanto quanto totalitária do espaço urbano 
(Berman, 1986; Callahan \& Ikeda, 2004). Seus projetos contrariavam o princípio de que as cidades possuem uma ordem espontânea de crescimento e que a vida urbana resulta, sobretudo, das interações sociais que lhe são características.

O Slum Clearance Committee, de Moses, colocou muitos edifícios e comunidades no chão em nome das técnicas construtivas e do progresso. Em meados dos anos 1950, três projetos previam a transformação de parte da região sudoeste de Manhattan em rodovias e condomínios. Dentre eles estavam a demolição de 14 quadras no West Village e a destruição de inúmeros edifícios do século XIX, onde hoje fica o SoHo, para a construção de uma via expressa. Liderada por donas de casa, ativistas e moradores, incluindo Jane Jacobs, a resistência obrigou a prefeitura de Nova York a desistir dos projetos, inspirando a criação da Landmarks Preservation Commission, em 1965, o primeiro grupo de preservação histórica dos Estados Unidos (Callahan \& Ikeda, 2004).

Entre os anos 1950 e 1970, o modelo de urbanização em larga escala imposto por Moses sempre foi contraposto por filosofias mais modestas e preservacionistas de urbanização. No entanto, entre o final dos anos 1970 e 1980, novas iniciativas de reformulação urbana com finalidades econômicas e políticas voltaram a ser comandadas pela especulação imobiliária. Dos anos 1990 em diante, o enobrecimento e a revitalização urbana tornaram-se sistemáticos, assumindo uma função estratégica e generalizada na disputa entre as cidades globais. A estas três etapas Neil Smith (2006) chamou de primeira, segunda e terceira ondas de revitalização urbana em Nova York.

\section{As três ondas de revitalização urbana em Nova York}

De acordo com Smith, a primeira onda teve um caráter bastante pontual, localizada em bairros como Greenwich Village, Upper West Side e Soho, entre os anos 1950 e meados dos anos 1970. Embora tenha sido marcada pelo fluxo de habitantes de classes média e alta para bairros originalmente ocupados por imigrantes de classe baixa do leste europeu, configurando os primeiros processos de gentrification, Smith destaca uma orientação cultural, mais até do que econômica, em reação às características excessivamente padronizadas dos principais centros comerciais ou residenciais da cidade.

A segunda onda de revitalização foi marcada por uma significativa crise econômica e política, que teve seu auge no ano de 1975 . O endividamento do município, a desvalorização imobiliária das áreas centrais decorrente da transferência de moradia das classes média e alta para os subúrbios e as crises fiscal e econômica dos anos 1980 constituíram um cenário ideal para a especulação. Com o apoio do município, o financiamento de programas habitacionais foi facilitado e, em poucos anos, regióes como Lower East Side, Brooklyn e Harlem também foram sendo reformuladas.

Após a queda da Bolsa de Nova York em 1987, que afetou os aluguéis e as taxas de financiamento para a construção, acreditou-se que as iniciativas de revitalização urbana chegariam ao fim. No entanto, o que ocorreu foram inúmeras outras, e não só de edifícios residenciais, mas também de lojas, escritórios, restaurantes e casas de 
espetáculo, constituindo uma nova forma de configuração do espaço urbano, agora marcada por processos generalizados de enobrecimento.

Atualmente, pode-se dizer que a revitalização urbana e a gentrification generalizada, tal como definidas por Smith (2006), resultaram em um novo modelo de urbanização, facilitado tanto pelo poder público através da revisão dos critérios de zoneamento da cidade, quanto por associações comerciais cada vez mais fortes e inseridas na gestão do espaço urbano ${ }^{7}$ (Zukin, 2010). Com isso, os intuitos preservacionistas, mesmo que poéticos ou utópicos de se cultivar o aspecto cultural dos lugares, foram sendo paulatinamente substituídos por outras formas de preservação, que tendem a transformar os traços históricos em meros elementos estéticos, como o porquinho de louça que se pode ver à porta da Destination Art Space, no Meatpacking District.

\section{FIGURA 1 | Destination Art Space}

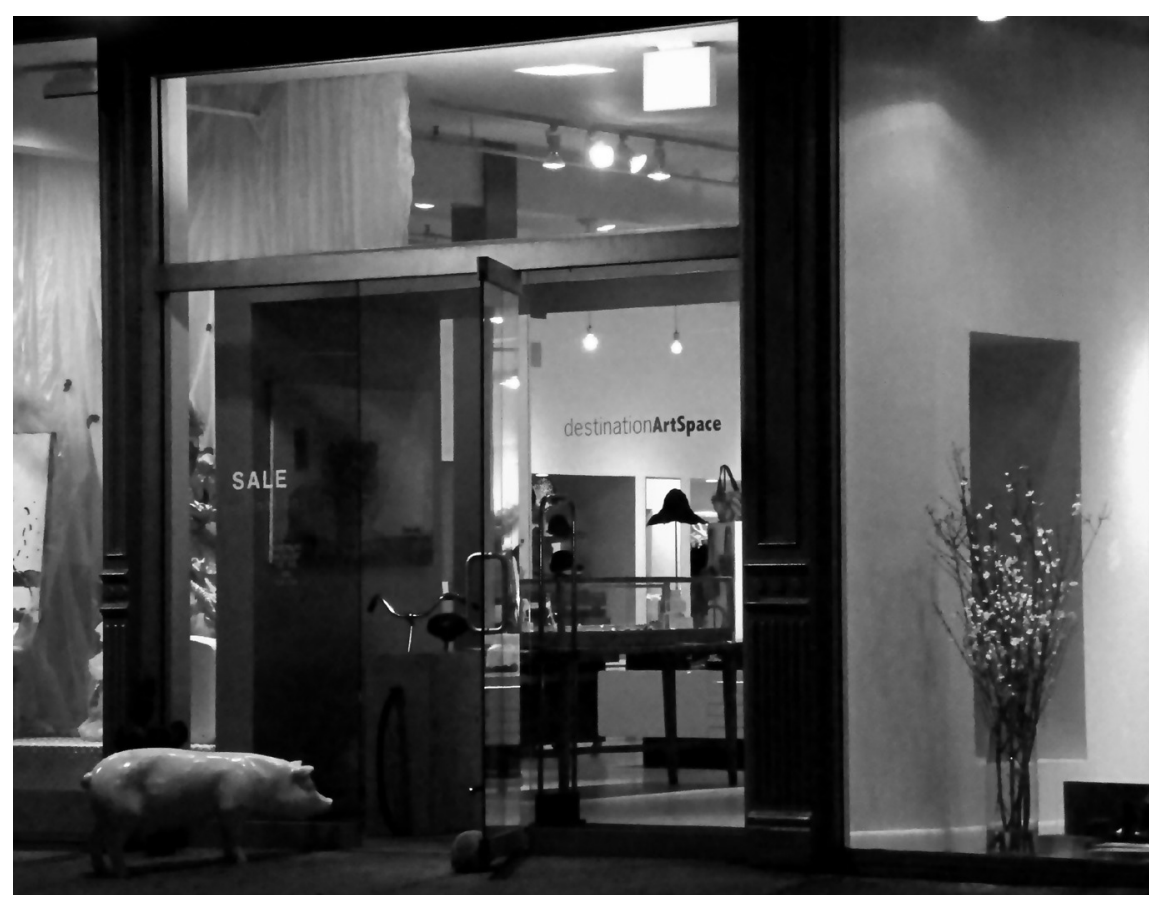

FONTE FOTOS DA AUTORA.

7 Em Manhattan, cresce cada vez mais o número e a influência dos chamados Business Improvement Districts, associações comerciais fortalecidas e inseridas na gestão da cidade que, através da arrecadação de recursos entre seus filiados, vêm promovendo projetos e iniciativas de revitalização urbana, segurança e administração de serviços em suas áreas de atuação. Os BID's de Times Squares e Union Square são dois exemplos importantes de associações, em Manhattan, capazes de gerenciar o espaço público de ruas e praças segundo critérios evidentemente privados. 


\section{O Meatpacking District}

O Meatpacking District compreende uma região de 18 hectares situada na parte sudoeste de Manhattan e fica entre a Rua 14 e o Rio Hudson, nas imediações do Chelsea. Em 1884, com a criação do Mercado Gansevoort — o nome homenageia o avô de Hermann Melville, autor de Moby Dick- o distrito tornou-se um dos maiores produtores de carne dos Estados Unidos. Em 1900, havia na região cerca de 250 matadouros, empacotadores de carne e distribuidores, cujos negócios foram ainda mais impulsionados pela construção, em 1934, de uma linha suspensa de trem que ligava as docas do rio Hudson ao bairro, transportando animais.

Nos anos 1960, a produção e o comércio de alimentos foram transferidos para regiões mais periféricas da cidade, tanto por uma questão de espaço quanto de saúde pública. Grandes centros de produção e distribuição foram abertos na região de Hunts Point, no Bronx, uma área industrial atualmente conhecida como o maior centro de distribuição de comida do mundo. No Hunts Point foram construídas, por exemplo, as novas instalações do Fulton Fish Market, antes situado na região do Meatpacking District. O novo mercado de peixe, planejado durante a gestão do prefeito Rudolph Giuliani, custou cerca de 85 milhões de dólares e transferiu de Manhattan para o Bronx cerca de 55 comerciantes de pequeno e médio portes (New York Magazine, 2006).

Nos anos 1970, com os primeiros processos de gentrification de bairros como SoHo e Tribeca, certas ocupações características destes bairros — como a presença de artistas, lojas de produtos underground, galerias de arte alternativas, pequeno comércio de drogas e prostituição - começaram a se deslocar para a região do Meatpacking District que, predominantemente comercial, tornava-se vazia durante a noite. No início dos anos 1980, diversas casas de show, strip-tease e prostituição transexual haviam sido abertas na região; fechadas no início dos anos 1990, deram lugar aos primeiros pequenos e charmosos restaurantes do bairro.

Até o final da década de 1990, no entanto, um número considerável de artistas e designers ocupou e desocupou os andares superiores dos açougues do Meatpacking, tendo em vista os baixos e depois os altos preços dos alugueis. Por volta do ano 2000, ameaçados de demolição, tanto o Mercado Gansevoort quanto a linha suspensa de trem tornaram-se alvo de interesse da comunidade local e de grupos ligados à preservação do patrimônio histórico.

Em 2003, somente 35 dos 250 matadouros originais ainda permaneciam no Meatpacking District, dando lugar a boutiques de estilistas famosos como Stella McCartney, Alexander McQueen e [o brasileiro] Carlos Miele, assim como a lofts e redes de bares e restaurantes internacionais como Lothus, Buddha Bar e Cielo. Sete anos depois, ou seja, em abril de 2010, o número de empacotadores de carne do distrito era de apenas 8 . Concentrados em um pequeno quarteirão da Rua Washington, eles abastecem os caminhões entre 5 e 8 da manhã, fornecendo cortes especiais para restaurantes de luxo da cidade ${ }^{8}$.

8 Fonte: análise de fontes secundárias, observaçôes participantes e entrevistas semiestruturadas, realizadas pela autora entre dezembro de 2009 e abril de 2010. 
Isso significa dizer que, no Meatpacking District, os Homens de Branco foram substituídos pelos Homens de Preto. Quase não se vê mais os primeiros que, de botas e jalecos brancos, transitavam pelas calçadas com pedaços de carne nos ombros, carregando caminhões refrigerados, no final dos anos 1990. No lugar deles há manobristas e seguranças por toda parte, com seus ternos pretos, ilustrando com ar blasé as pequenas ruas do distrito, tomadas por jovens bem vestidos dispostos a pagar, pelo menos, 25 dólares por um drink ou 85 por uma camiseta de malha na Hugo Boss, uma grife que, entre orquídeas, bromélias e aromatizantes, música brasileira e madeira de demolição, preserva o piso e as colunas de cimento de um açougue onde, há alguns anos, estivera ali, quase na esquina da Rua 14 com a 9a Avenida.

A construção do hotel Gansevoort em 2004 e de edifícios de luxo, a criação da High Line - o parque construído na antiga linha suspensa de trem que implicou investimentos públicos e privados de cerca de 80 milhões de dólares e que, inaugurado em junho de 2009, já recebeu mais de 2 milhões de visitantes —, além do anúncio de se transferir, para a região, a sede do Whitney Museum of American Arts, com projeto do renomado arquiteto italiano Renzo Piano, vêm fazendo do Meatpacking District, segundo a revista New Yorker, a vizinhança mais fashion de Manhattan.

\section{FIGURA 2 | Mapa do Meatpacking District}

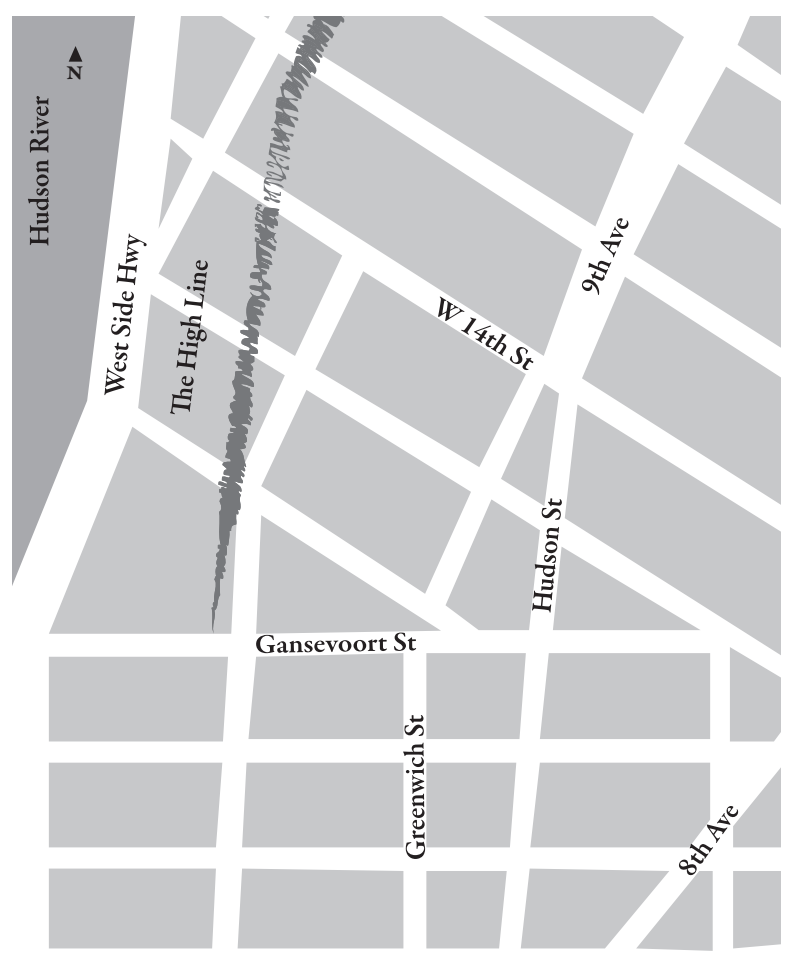




\section{A influência do urbanismo europeu no Brasil}

No Brasil, os grandes projetos de urbanização implantados em cidades como Rio de Janeiro e São Paulo foram inspirados, desde o final do século XIX, pelo modelo higienista do Barão George Eugéne Haussmann, adotado em Paris entre 1853 e 1870, quando prefeito da cidade. As primeiras intervenções no centro de São Paulo, bem como a conhecida reforma urbana de Pereira Passos no Rio de Janeiro (1902-1906), foram tentativas de se estabelecer, nas duas maiores cidades do país, padrões do que deveria ser, segundo Sandra Pesavento (1999), a metrópole moderna brasileira: o sonho de uma Paris tropical.

Apesar das primeiras iniciativas de urbanização terem ocorrido com a vinda da corte portuguesa para o Brasil, em 1808, foi somente no final do século XIX que o Rio de Janeiro passou a consolidar-se como metrópole nacional, embora marcada por hábitos ainda colonialistas. Centro de escoamento da produção cafeeira, a cidade crescia em torno do cais, assim como suas dinâmicas de industrialização e de povoamento. Com isso, também cresciam os problemas de moradia, segurança, transporte e limpeza pública que, com o surto de febre amarela, no final dos anos 1890 , passaram a exigir um rígido e também controverso controle sanitarista por parte do governo municipal.

De cidade exótica e colonial, o Rio de Janeiro queria ser moderno. Este foi o desejo que pautou os primeiros grandes projetos de urbanização da cidade caracterizados, sobretudo, pela demolição de becos, cortiços e sobrados que pudessem dar lugar a grandes aterros e largas avenidas. A demolição do Cabeça de Porco na gestão do prefeito Barata Ribeiro, em janeiro de 1893, é um exemplo da intervenção do poder público nos processos de modernização da cidade. O Cabeça de Porco, um cortiço com cerca de 4 mil habitantes, era o "símbolo da cidade que deveria ser destruída, emblema da identidade urbana renegada do Rio que deveria sumir diante dos ventos do progresso" (Pesavento, 1999, p. 171). Derrubado em menos de 24 horas, o desalojamento de seus moradores deu início a uma das primeiras favelas da cidade, formada pelos antigos ocupantes do cortiço que, autorizados pela prefeitura, reaproveitavam madeira e restos da demolição para construir suas novas "moradias".

\section{A modernização de São Paulo}

Em São Paulo, as iniciativas de intervenção urbana tiveram objetivos mais ou menos semelhantes aos que orientaram os projetos de urbanização do Rio de Janeiro: uma expectativa das elites aristocráticas de conferir à cidade um caráter metropolitano e pretensamente cosmopolita, tendo em vista o crescimento econômico ocasionado pela exportação do café e, posteriormente, pelos primeiros impulsos de industrialização, além dos fluxos de imigração italiana, espanhola, japonesa e sírio-libanesa incentivados pelo fim da escravidão, em 1888, resultando em bairros até hoje ocupados por uma maioria estrangeira, como o bairro italiano do Bexiga e o bairro japonês da Liberdade, conhecido como a maior colônia japonesa do mundo, fora do Japão. 
No final do século XIX e princípio do século XX, começaram em São Paulo os primeiros esforços mais efetivos para se construir um centro arquitetônica e urbanisticamente condizente com os referenciais metropolitanos europeus. Segundo Frúgoli (2000), as gestões dos prefeitos Antônio Prado (1899-1910) e Francisco Prestes Maia (1938-1945) foram marcadas por iniciativas de reformulação do espaço urbano, de acordo com o modelo urbanístico parisiense. Projetos de alargamento de ruas, ordenação do tráfego, arborização de praças e construção de edifícios inspirados na arquitetura europeia são exemplos de uma série de iniciativas que visavam à modernização de São Paulo.

Segundo Sevcenko (1992), a criação e a reurbanização de praças e parques Praça da República (em 1905) e Vale do Anhangabaú (em 1910)- a construção de viadutos - Viaduto do Chá (em 1892) e de Santa Ifigênia (em 1913) - e de edifícios inspirados na arquitetura europeia - Teatro Municipal (em 1911), Mercado Central (em 1932) e Estação da Luz (em 1901)-, são exemplos da utilização de técnicas tipicamente modernistas e progressistas de urbanização. Além disso, representavam uma cidade, como se pode ler ainda hoje no site da prefeitura de São Paulo, "que nada queria dever aos grandes centros culturais do mundo naquele início de século”.

\section{A Região da Luz}

A primeira Estação da Luz, idealizada pelo Barão de Mauá, foi construída entre 1856 e 1867 pela estrada de ferro inglesa The Sao Paulo Railway e fazia o trajeto entre Jundiaí e Santos, de onde o café produzido no interior do estado era exportado. Entre 1895 e 1900, não atendendo à crescente demanda da produção e da exportação cafeeiras, a estação foi ampliada. Projetada em estilo neoclássico pelo arquiteto inglês Charles Henry Driver e reconstruída em estrutura de aço importada de Glasgow, a estação foi reinaugurada em março de 1901. Em 1946 foi quase totalmente destruída por um incêndio criminoso. Em 1947 a estrada de ferro inglesa foi nacionalizada, passando a chamar-se Estrada de Ferro Santos-Jundiaí. Somente em 1951 foram concluídas as obras de reconstrução e o edifício, acrescido de mais um pavimento e uma plataforma central, passou a ser usado pela Companhia Paulista de Trens Metropolitanos (São Paulo 450 anos, 2007).

Localizada em uma região central e já bastante deteriorada da cidade, a região da Luz compreende uma área de aproximadamente 450 mil metros quadrados, ou 111,2 hectares, seis vezes maior que a região do Meatpacking District, em Nova York. Na região situa-se o Complexo Cultural Julio Prestes, formado: i) pelo $\mathrm{Mu}$ seu da Língua Portuguesa, construído entre 2000 e 2006 nos antigos setores administrativos da Estação da Luz; ii) a restaurada Estação Júlio Prestes, onde fica a Sala São Paulo, sede da Orquestra Sinfônica do Estado de São Paulo (OSESP) e considerada a sala de concertos mais moderna da América Latina; iii) o Parque da Luz, tombado pelo Patrimônio Histórico no início dos anos 1980; iv) a Pinacoteca do Estado, uma construção de arquitetura neoclássica construída em 1905 e restaurada entre 1993 e 1998, que abriga cerca de 8 mil obras de arte brasileira dos séculos 
XIX e XX; v) o Memorial da Resistência, construído no edifício que abrigou, entre os anos 1940 e 1980, o Departamento Estadual de Ordem Política e Social (Deops) de São Paulo, órgão de repressão política da ditadura militar brasileira.

\section{FIGURA 3 | Mapa da Região da Luz}

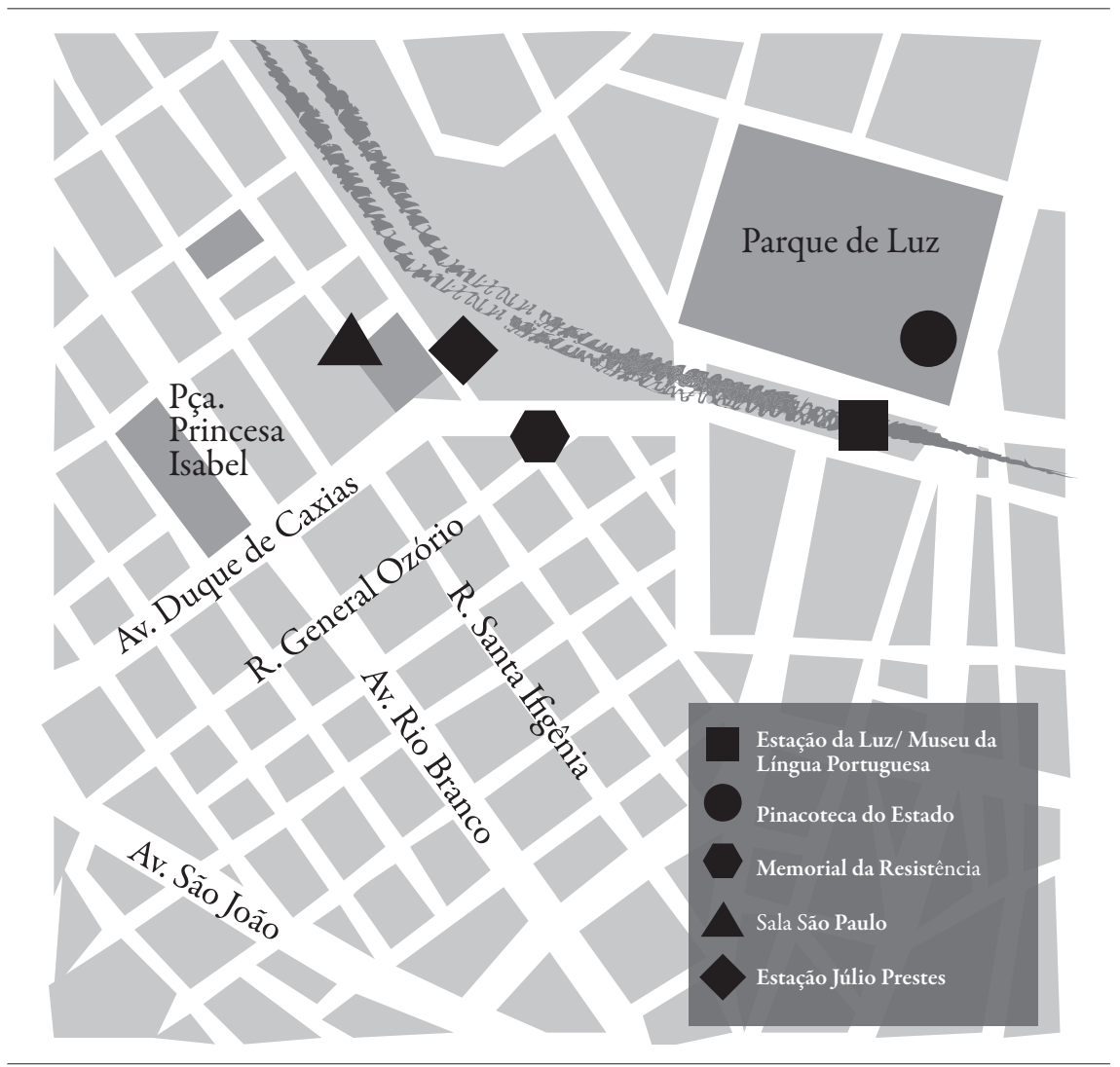

fonte Ilustração de Claudio Parreiras para a Autora

Afora algumas ações de cunho assistencialista, modestamente realizadas no final dos anos 1990, foi desde a inauguração do Museu da Língua Portuguesa, em 2006, que a revitalização da Luz passou a visar novas apropriações do lugar, marcadas pela alta cultura e com vistas a uma reocupação residencial da região pela classe média, tão incomum nas revitalizações de antigas áreas centrais, no Brasil. Gilberto Kassab, prefeito de São Paulo, espera que a Nova Luz seja uma referência internacional em projetos de revitalização urbana, aos moldes de cidades como Nova York e Barcelona: "pelo que tenho conversado com nossos técnicos, com os empresários, não tenho dúvida de que em pouco tempo essa região será um exemplo de urbanismo para o mundo todo" (Associação Brasileira dos Escritórios de Arquitetura, 2010). 
Para isso, a própria prefeitura definiu quem ela quer que sejam os pioneiros ${ }^{9}$ na reocupação da Luz: arquitetos, artistas gráficos, músicos e profissionais liberais, tal como se pode ver nas pranchas de apresentação do projeto de revitalização disponibilizadas no site da prefeitura de São Paulo. Trata-se de uma intenção que desconsidera um comércio de aproximadamente 100 empresas de acessórios para automóveis e motocicletas, cerca de 1.000 lojas de eletroeletrônicos e mais de 10 mil moradores com renda média de até 3 salários mínimos, segundo dados da prefeitura e da associação de amigos e comerciantes do bairro. Isso sem mencionar os cortiços, os edifícios e quarteirões abandonados, as pequenas casas de prostituição, os moradores de rua e um intenso comércio de drogas observado em pesquisa de campo realizada entre janeiro e fevereiro de 2011 que, reunidos, deram à região o apelido de Cracolândia.

Ironicamente, as próximas etapas de revitalização da Luz preveem, segundo a prefeitura, investimentos da ordem de 2 bilhões de reais, supostamente destinados à recuperação de uma área definida pelo Plano Diretor Estratégico de 2002 como Zona Especial de Interesse Social (ZEIS). Segundo estabelecido pela legislação municipal, 40 por cento da região deverá ser ocupada por habitações de interesse social voltadas para famílias com renda de até 5 salários mínimos; 40 por cento por imóveis destinados a famílias com renda de até 16 salários mínimos e 20 por cento destinada a usos livres (Jornal O Estado de São Paulo, 2009).

No entanto, a ideia de deixar os processos de revitalização a cargo de construtoras e de empresas de arquitetura e urbanismo de renome internacional começou com reuniões realizadas entre a prefeitura de São Paulo, incorporadores imobiliários e construtores, em 2005, quando o sindicato das empresas do setor imobiliário (Secovi) contratou o arquiteto Jaime Lerner para elaborar um novo plano urbanístico para a região. A proposta foi doada por Lerner à prefeitura, mas nunca implantada, e previa a construção de torres comerciais de 80 andares e mais de 200 metros de altura; um boulevard na Avenida Rio Branco, cercado de altos edifícios; 16 quadras de uso misto, com prédios com altura máxima de 8 pavimentos; além da reurbanização das avenidas Duque de Caxias, Ipiranga e Cásper Líbero.

Em outubro de 2009, o sindicato das empresas do setor imobiliário abandonou a proposta de Lerner, alegando que o zoneamento da região, demarcado por áreas de interesse social, implicaria a construção de moradias populares com pequena margem de lucro para os investidores, favorecendo a formação de enclaves de ocupação popular e restringindo o interesse da classe média pelo local. Logo em seguida, o então governador de São Paulo, José Serra, contratou o escritório de arquitetura suíço Herzog \& De Meuron para projetar outro grande equipamento cultural na região, o Teatro da Dança, a fim de impulsionar a revitalização e, com ela, o enobrecimento da Luz. O espaço, cujo término está previsto para 2014, deve custar cerca de 600 milhões de reais, conforme reportagem publicada pelo Jornal $O$

9 Pioneiros no sentido proposto por Smith (2006) ao descrever a primeira onda de revitalização urbana em Nova York, marcada pela ocupação de antigas regiōes industriais da cidade, por volta dos anos 1950, por grupos de artistas e ativistas sociais de classe média. 
Estado de São Paulo em abril de 2010, e será construído no prédio da antiga rodoviária da cidade, desapropriado por 34 milhões e no qual funcionou, entre $1982 \mathrm{e}$ 2007, um shopping de roupas populares.

Tão logo o projeto do Teatro da Dança foi contratado, abriu-se o processo de concorrência pública para a seleção de ideias destinadas à revitalização integral da Luz, tal como vem sendo conduzida atualmente. Oito consórcios se candidataram, mas apenas cinco apresentaram a documentação necessária. A concorrência foi finalizada em dezembro de 2009. Em março de 2010, após tentativas mal sucedidas de embargo por supostos favorecimentos à equipe vencedora, o consórcio internacional ganhador assinou contrato com a prefeitura, comprometendo-se a apresentar à comunidade, no início de 2011, a primeira proposta de revitalização (Jornal $O$ Estado de São Paulo, 2010).

A primeira audiência pública, prevista para março, foi agendada para o dia 14 de janeiro de 2011 e cancelada porque o espaço programado não comportava o número de participantes. Remarcada para o dia 28 de janeiro, o que pretendia ser uma experiência de governança urbana compartilhada terminou em atos de violência entre representantes da prefeitura e integrantes da associação comercial do bairro de Santa Ifigênia. ${ }^{10}$ Com as liminares judiciais obtidas por ações populares cassadas em fevereiro de 2012, o projeto da Nova Luz deve seguir adiante até o final de 2012, quando as fases subsequentes da revitalização urbana se tornarão objeto de uma nova concorrência pública, a de concessão urbanística, com implantação a cargo da iniciativa privada e estimada em aproximadamente 1 bilhão de reais (Rodrigues \& Burgarelli, 2012).

\section{Conclusões}

Segundo Jacobs (2000), pensar a revitalização urbana por meio de projetos, como vem ocorrendo em São Paulo, é não levar em conta a natureza peculiar das cidades, já que tendem a reproduzir os problemas que levaram à degradação inicial, como a ausência de dinamismo ou de usos combinados de pessoas em suas atividades cotidianas de trabalho, deslocamento, moradia e lazer.

No caso do Meatpacking District e ao contrário da Região da Luz, já não é possível falar em projetos, mas em processos, e esta é a principal diferença entre os casos estudados em Nova York e São Paulo. Iniciado e catalisado por grupos de artistas instalando seus ateliês em uma área originalmente industrial da cidade, o ciclo de revitalização urbana do Meatpacking District parece completar-se de modo mais orgânico que no caso brasileiro. Trata-se de um princípio de contingência, no sentido proposto por Becker (1996); o que não significa dizer que ele tenha ocorrido de forma inteiramente espontânea. A presença de vultosos investimentos imobiliários na construção de hotéis, lojas de grife e restaurantes de prestígio, bem como a revisão nos critérios de zoneamento urbano da região, por parte da prefeitura, ambos

Reunião acompanhada, em São Paulo, por meio de observação participante. 
necessários à instalação de novas formas de uso e apropriação do lugar, podem ser tomados como exemplos de intervenção.

Como resultado, pode-se destacar o fato de que os cerca de 170 estabelecimentos comerciais do Meatpacking District, catalogados pela associação comercial e contabilizados em pesquisa de campo realizada entre dezembro de 2009 e abril de 2010, podem ser divididos em apenas cinco categorias: i) bares e restaurantes; ii) galerias de arte; iii) boutiques de luxo; iv) hotéis de charme; e v) salões de beleza ou spas urbanos; o que, em termos funcionais, representa uma forma predominante de apropriação.

FIGURA 4 | Mapa das categorias de ocupação da região do Meatpacking District

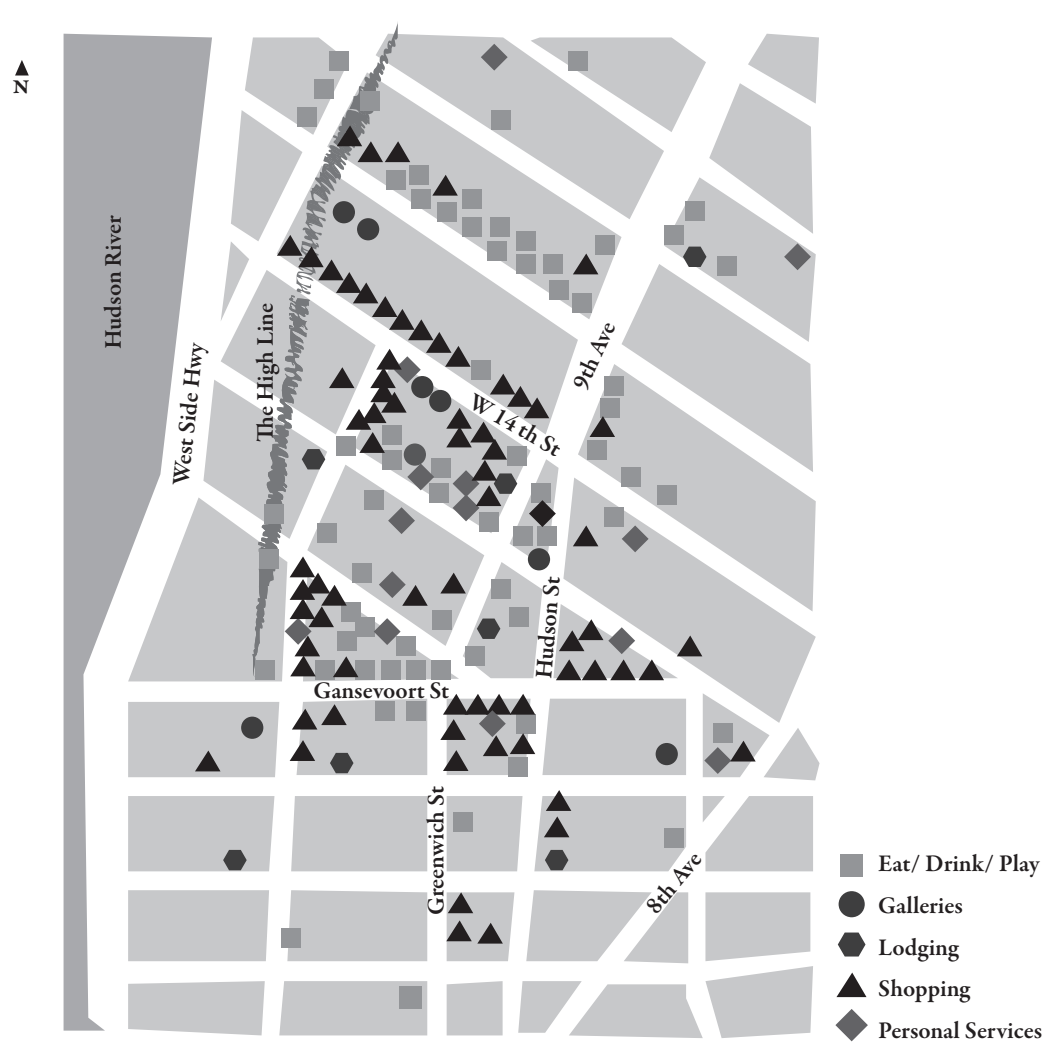

fonte Ilustração de Claudio Parreiras para a autora.

Para além da distinção entre processos e projetos, ou das restrições à diversidade de usos encontrada em ambos os casos estudados, é importante destacar outras duas variáveis na análise comparativa das revitalizações urbanas do Meatpacking District, em Nova York, e da Região da Luz, em São Paulo: os agentes da revitalização e os efeitos delas resultantes. 
Em São Paulo, o papel do poder público como articulador dos projetos de revitalização urbana é preponderante; a revitalização da Luz, por exemplo, vem sendo discutida por sucessivos governos municipais há mais de 20 anos. Por um lado, a alocação de recursos públicos na revitalização de uma área tão significativa da cidade explica, em parte, por que a maioria dos projetos não saiu do papel. Por outro, a captação de recursos advindos de financiamentos internacionais de preservação do patrimônio histórico e arquitetônico, bem como de concessões públicas destinadas à exploração privada, acarretam alterações bastante significativas na natureza, em termos de ocupação, das regiões a serem revitalizadas. Isso também nos ajuda a entender por que os projetos, quando enfim implantados, acabam por ter vida curta. Invariavelmente, eles se caracterizam tanto por áreas destinadas à produção e ao consumo de alta cultura, como o Complexo Cultural Julio Prestes, quanto por projetos residenciais destinados à classe média em regióes de ocupação marcadamente popular, o que revela uma certa esquizofrenia nos projetos de revitalização urbana brasileiros, dos quais a Luz é metonímia: a de criarem ou fomentarem enclaves de uma segregação social às avessas, de nichos revitalizados e enobrecidos em áreas de uso, trânsito e ocupação marcadamente populares, como é o centro de São Paulo e de grande parte das cidades brasileiras.

Já em Nova York, há um ciclo mais extenso de reapropriação dos lugares e, conseqüentemente, de revitalização e gentrification. Ele começa, invariavelmente, com o interesse de artistas e intelectuais por regiões originalmente industriais da cidade, atraindo especuladores imobiliários interessados em edifícios decadentes ou terrenos desocupados, resultando, em alguns anos, em revitalizações e enobrecimentos contingentes ou orgânicos, dos quais o poder público é, na maior parte das vezes, mediador. Em Nova York, isso aconteceu em bairros como SoHo, Tribeca e Greenwich Village, nos anos 1960 e 1970, no Meatpacking District, desde meados dos anos 1980 e, mais recentemente, segundo Zukin (2010), em regióes como Brooklyn e Harlem, cuja completude dos processos de enobrecimento ou gentrifcation vem se tornando, a cada dia, mais aparente.

Ainda vale lembrar que tanto o Meatpacking District quanto a Região da Luz podem ser definidos como zonas de fronteira. Por serem um destino final, ou seja, ninguém costuma estar ali de passagem, já que portos e estações são, por definição, espaços limítrofes, seria preciso intervir de modo a reconectar as regiões revitalizadas ao seu entorno, e não favorecer uma apropriação predominante de consumo cultural ou de luxo, como se pode observar em ambos os casos: o de Nova York, já instaurado; o de São Paulo, como intenciona o atual projeto de revitalização.

Ao analisar intervenções urbanas em Pittsburgh, São Francisco e Filadélfia em seu livro Morte e vida das grandes cidades, Jane Jacobs (2000) ressaltou dois aspectos que considerava imprescindíveis às iniciativas de revitalização urbana que se pretendiam efetivas: a abertura de ruas ligando zonas de fronteira à malha urbana mais próxima e o desmembramento de edifícios históricos em pequenas unidades destinadas a usos ou funções diferentes e, consequentemente, a públicos também variados. Tanto em Nova York quanto em São Paulo é possível encontrar elemen- 
tos do espaço urbano original que comportariam uma e outra intervenções. Entretanto, em nenhum dos casos estudados foi possível identificar tais elementos como próprios a ambas as iniciativas de revitalização.

Guardadas as suas diferenças e similaridades, o Meatpacking District, em Nova York, e a Região da Luz, em São Paulo, parecem prescindir daquilo que Jacobs definira como a natureza peculiar das cidades: a ideia de que as ruas são um manifesto público das vocações de uma cidade, uma zona de convergência onde convivem os costumes e os anseios da vida urbana. $\mathrm{O}$ mundo da rua, para usar uma expressão de Benjamim (1985; 2006), é a cidade em miniatura, até mesmo um mundo em miniatura, sobre o qual passeia o olhar do escritor, do viajante, do pesquisador, mas, sobretudo, o olhar e o pulsar de quem vive ou transita pela cidade.

Tomando como ponto de referência o que tem resultado das iniciativas cada vez mais recorrentes de revitalização urbana, incluindo os casos aqui estudados, podese dizer que poucos lugares ainda parecem guardar esta diversidade de usos e de ocupações como algo intrínseco à natureza da vida urbana. A cidade, tantas vezes representada e imaginada pela diversidade - harmoniosa ou não - de classes sociais e etnias, ou por sua multiplicidade de funções e sociabilidades características, parece vir dando lugar a um conjunto cada vez maior de cenários destinados ao turismo e ao consumo de luxo e de cultura. Os mundos em miniatura se restringem; as cidades estão sendo passadas a limpo. OEURE

\section{Referências bibliográficas}

Associação Brasileira dos escritórios de Arquitetura (2010). Notícias. Disponível em http://www. asbea.org.br/escritorios-arquitetura/noticias/projeto-da-nova-luz-estara-pronto-no-fimdo-ano-133602-1.asp. Acesso em 02 fevereiro 2010.

Nolasco, C., Freitas, R. \& Batista, T. (2007). O planejamento urbano e a consagração da rua. Revista Eclética, 24 (Janeiro/junho), 47-51. Disponível em http://puc-riodigital.com.puc-rio.br/ cgi/cgilua.exe/sys/start.htm?infoid=2351\&sid=89\&tpl=printerview.

Becker, H. (1996). A Escola de Chicago. Mana, 2(2), 177-188. http://dx.doi.org/10.1590/S010493131996000200008

Benjamim, W. (1985). Paris, capital do século XIX. In W. Benjamim, Sociologia. São Paulo: Ática. Benjamim, W. (2006). Passagens. Belo Horizonte: Ed. Universidade Federal de Minas Gerais (UFMG). Berman , M. (1986). Tudo que é sólido desmancha no ar. São Paulo: Cia das Letras.

Botelho, T. (2005). Revitalização de centros urbanos no Brasil: uma análise comparativa das experiências de Vitória, Fortaleza e São Luís. EURE, 31(93), 53-71.

Bourdieu, P. (1999). A miséria do mundo. Petrópolis: Vozes.

Callahan, G. \& Ikeda, S. (2004). The career of Robert Moses: City planning as a microcosm of socialism. The Independent Review, 9(2, Fall).

Canclini, N. G. (1999). Consumidores e cidadãos: conflitos culturais da globalização. Rio de Janeiro: Ed. Universidade Federal do Rio de Janeiro (UFRJ). 
Canevacci, M. (2004). A cidade polifônica: um ensaio sobre a antropologia da comunicação urbana. São Paulo: Studio Nobel.

Elias, N. (1994). A sociedade dos indivíduos. Rio de Janeiro: Jorge Zahar Editores.

Frúgoli Jr, H. (2000). Centralidade em São Paulo: trajetórias, conflitos e negociações na metrópole. São Paulo: Cortez / Editora da Universidade de São Paulo.

Goffman, E. (1975). A representação do eu na vida cotidiana. Petrópolis: Vozes.

Greenberg, M. (2008). Branding New York: how a city in crisis was sold to the world. Nova York: Routledge.

Harvey, D. (1992). Condição pós-moderna. São Paulo: Edições Loyola.

Herzog, L. (2006). Return to the center: Culture, public space and city-building in a global era. Austin: University of Texas Press.

Jacobs, J. (2000). Morte e vida de grandes cidades. São Paulo: Martins Fontes.

Jornal O Estado de São Paulo. (2009, 28 Abril). AIB paga e Lerner projeta Nova Luz. Disponível em http://www.estadao.com.br/estadaodehoje/20090428/not_imp361660,0.php. Acesso em 02 fevereiro 2010.

Jornal O Estado de São Paulo. (2009, 29 Outubro). Mercado imobiliário abandona Nova Luz. Disponível em http://www.estadao.com.br/estadaodehoje/20091029/not_imp458017,0.php. Acesso em 02 fevereiro 2010.

Jornal O Estado de São Paulo. (2010, 14 Maio). Plano de revitalização da Nova Luz começa a ser executado em 17 de junho. Disponível em http://www.estadao.com.br/noticias/cidades,planode-revitalizacao-da-nova-luz-comeca-a-ser-executado-em-17-de-junho,551890,0.htm. Acesso em 07 novembro 2010.

Lefebvre, H. (1991). O direito à cidade. São Paulo: Ed. Moraes.

Lynch, K. (1960). The image of the city. Cambridge, MA: The MIT Press.

Lipovetsky, G. (2000). O império do efêmero: a moda e seu destino nas sociedades modernas. São Paulo: Companhia das Letras.

New York Magazine. (2006). Hunts Point in 2016. Disponivel em nymag.com/realestate/features/2016/17150/. Acesso em 06 fevereiro 2010.

New York Public Library (2010). Mapping New York's shoreline: Celebrating the quadricentennial of Henry Hudson's exploration of the waterways of New York, 1609-2009 [Exhibition]. Nova York, setembro 2009-junho 2010.

Park, R. (1987). A cidade: sugestões para a investigação do comportamento humano no meio urbano. In: O. G.Velho, Otávio (Org.), O fenômeno urbano. Rio de Janeiro: Guanabara.

Pesavento, S. (1999). O imaginário da cidade: visöes literárias do urbano - Paris, Rio de Janeiro, Porto Alegre. Porto Alegre: Ed. Universidade / Universidade Federal do Rio Grande do Sul (UFRGS).

Rodrigues, A. \& Burgarelli, R. (2012). Tribunal cassa liminares e libera Nova Luz. Disponível em http://www.estadao.com.br/noticias/impresso,tribunal-cassa--liminares-e-libera-novaluz-,840518,0.htm > Acesso em 26 fevereiro 2012

Sassen, S. (2001). The global city: New York, London, Tokio. Princeton: Princeton University Press.

São Paulo 450 anos. (2007). Disponível em <http://www.aprenda450anos.com.br/450anos/vila_metropole/2-3_estacao_luz.asp > Acesso em 05 setembro 2009. 
Sevcenko, N. (1992). Orfeu Extático na Metrópole: São Paulo nos frementes anos 20. São Paulo: Companhia das Letras.

Silva, N. (2004). Ícones da Metrópole. Muito+ A Revista da Região Metropolitana de Campinas, 1(1), 23-29.

Smith, N. (2006). A gentrificação generalizada: de uma anomalia local à "regeneração" urbana como estratégia urbana global. In: C. Bidou-Zachariasen, De volta à cidade: dos processos de gentrificação às políticas de "revitalização" dos centros urbanos. São Paulo: Annablume.

Simmel, G. (1972). Metrópole e vida mental. In: O. G. Velho, (Org.), O fenômeno urbano. Rio de Janeiro: Zahar Ed.

Talese, G. (2004). Fama e anonimato. São Paulo: Cia das Letras.

Velho, G. (1987). Individualismo e cultura: Notas para uma antropologia da sociedade contemporânea. Rio de Janeiro: Jorge Zahar Editores.

Wilheim, J. (2005). Cidades: o que há de novo? Revista AU - Arquitetura e Urbanismo, 137(20), 62-69.

Wood, A. (2008). Preserving New York: Winning the right to protect a city's landmarks. Nova York: Routledge.

Zukin, S. (2009). Naked city: The death and life of authentic urban places. Nova York: Oxford University Press.

Zukin, S. (2000). Paisagens urbanas pós-modernas: mapeando cultura e poder. In: A. A. Arantes (Org.), O Espaço da Diferença. Campinas: Papirus. 